\title{
One year after the Zika virus outbreak in Brazil: from hypotheses to evidence
}

\author{
Carlos Alexandre Antunes de Brito ${ }^{[1]}$ and Marli Tenorio Cordeiro ${ }^{[2]}$
}

\author{
[1]. Departamento de Medicina Clínica, Universidade Federal de Pernambuco, Recife, Pernambuco, Brasil. \\ [2]. Departamento de Virologia, Centro de Pesquisa Aggeu Magalhães, Fundação Oswaldo Cruz, Recife, Pernambuco, Brasil.
}

\begin{abstract}
Zika virusis an arbovirus of the Flaviviridae family with two major strains, an Asian and an African strain. The main vectors involved in the transmission of Zika virus are the Aedes aegypti and Aedes albopictus mosquitoes. Despite its identification, discovered in 1947 in the Zika forest in Uganda, only isolated and sporadic occurrences of human infection were reported within a largely asymptomatic proportion of individuals. The first reported outbreak occurred in 2007 in the Yap Island, which belongs to the Federated States of Micronesia in the Pacific Ocean, and in French Polynesia, where high attack rates occurred and the first cases of associated Guillain-Barré syndrome were reported. From November 2014 to early 2015, the Northeast states of Brazil reported the first outbreaks of Zika virus infection, with laboratory confirmation of Zika virus circulation in April 2015. In the second quarter of 2015, the association between Zika virus infection and neurological symptoms was confirmed in adults. Moreover, in October 2015 a novel suspicion was raised based on clinical and epidemiological observations: that an association between Zika virus infection and neonatal microcephaly may exist. A year after the first reports on Zika virus in Brazil, many hypotheses and much evidence on the patterns of involvement of the disease and its complications have been produced, both in this country and others; other hypotheses still need to be clarified. This review is a synthesis of a new chapter in the history of medicine; it outlines the main results produced.
\end{abstract}

Keywords: Zika. Microcephaly. Neurological cases. Epidemiology. Review.

\section{INTRODUCTION}

Zika virus (ZIKV) is an arbovirus of the Flaviviridae family with two major strains identified, the Asian and African strains. The main vectors involved in its transmission are the Aedes aegypti and Aedes albopictus mosquitoes. Although it was first identified in 1947 in the Zika forest in Uganda, only isolated and sporadic occurrences of human infection were reported within a largely asymptomatic proportion of individuals ${ }^{(1)(2)(3)}$. The first outbreak was reported in 2007 in Yap Island, which belongs to the Federated States of Micronesia in the Pacific Ocean ${ }^{(4)}$, and in French Polynesia, where high attack rates occurred and the first cases of associated Guillain-Barré syndrome (GBS) were observed and reported ${ }^{(5)(6)(7)}$.

From November 2014 to early 2015, the Northeast states of Brazil reported the first outbreaks of ZIKV infection; virus circulation was laboratory confirmed in April $2015^{(8)(9)}$. In the second quarter of that year, the association between ZIKV infection and neurological symptoms/signs in adults was

Corresponding author: Dr. Carlos Alexandre Antunes de Brito.

e-mail: cbritoc@gmail.com

Received 16 August 2016

Accepted 7 October 2016 confirmed. Moreover, in October 2015, a novel hypothesis was suggested, that ZIKV infection and neonatal microcephaly are associated, based on clinical and epidemiological observation and investigation ${ }^{(10)(11)(12)}$.

A year after the first reports on ZIKV in Brazil, many hypotheses have been made and much evidence produced on the patterns of involvement of the disease and its complications; other hypotheses still need to be clarified. This review is a synthesis of a new chapter in the history of medicine; it outlines the main results produced, both in Brazil and elsewhere.

\section{EPIDEMIOLOGY}

ZIKV had been the subject of few published studies before 2007; cases of ZIKV infection occurred sporadically and followed an oligosymptomatic clinical presentation ${ }^{(2)(3)}$. Despite a paucity of information about the techniques employed for the diagnosis of ZIKV infection, some small prevalence studies were published. In Uganda in 1984, antibodies to Zika were detected in $6 \%$ of 132 blood samples obtained from adults ${ }^{(13)}$. In Nigeria in $1979,31 \%$ and $38 \%$ of 189 serum bank samples tested positive for ZIKV through Zika hemagglutination inhibition or detection of neutralizing antibodies, respectively ${ }^{(14)}$.

The change in the disease pattern was initially noted in 2007 on Yap Island with confirmation of ZIKV by reverse transcription polymerase chain reaction (RT-PCR) in 10 of 
71 serum samples. Of 185 suspected cases of ZIKV infection in the health centers, $49(26 \%)$ were laboratory confirmed. In addition, ZIKV infection was suspected and tested for in 557 family members related to these cases; immunoglobulin $\mathrm{M}$ (IgM) antibodies against ZIKV were positive in 74\% (414/557), and only $38 \%$ of these $(156 / 414)$ reported symptoms that met the criteria for suspected ZIKV infection. The attack rate was estimated at 14.6 per 1,000 inhabitants, given a seroprevalence of $72 \%$ of the population over a 3 -year period and considering that only $18 \%$ of infected individuals became symptomatic ${ }^{(4)}$.

In 2013, French Polynesia registered a large ZIKV outbreak. Data reporting on the outbreak was more robust, with high attack rates and neurological complications reported. A serological study among blood bank donors conducted before the outbreak in 2013 demonstrated that, prior to the outbreak, ZIKV was not in circulation in this country ${ }^{(15)}$. During the outbreak, 8,262 suspected cases were reported in the sentinel units. A total of 746 serum samples were tested, 396 (53.1\%) tested positive for ZIKV by RT-PCR. Overall, there were more than 29,000 estimated cases, with an attack rate of $10 \%{ }^{(5)(7)}$.

In Brazil, the first reports on suspected cases occurred in the Northeast, with a peak in the first quarter of 2015. A large outbreak of an exanthematic, arthritogenic disease with a clinical pattern different from dengue, made Dr. Kleber Luz (an infectologist in Rio Grande Norte, Brazil) raise the hypothesis of ZIKV infection. This was only confirmed in April 2015, when 8 of 25 serum samples in Bahia and, subsequently, 8 of 21 cases in Rio Grande do Norte tested positive for ZIKV ${ }^{(8)(9)(10)}$.

The outbreak demonstrated a high attack rate with thousands of people affected. This led to over crowding of public and private emergency services. However, the outbreak was not measured by official notification systems, as it was not mandatory to notify cases of the disease. The Secretaries of Health Surveillance advised that cases physicians suspected of being due to ZIKV infection be notified as cases of dengue ${ }^{(16)}$.

In the fourth quarter of 2015, as the critical stage of the Zika outbreak passed, the epidemiologic bulletin on arboviral infections in Pernambuco (one of the states with the highest number of cases) reported that 122,665 cases of dengue and only 4 cases of Zika were notified ${ }^{(17)}$. A study conducted in the emergency unit of a referral hospital identified 1,200 suspected cases of arboviral infections: $84 \%$ met the clinical criteria for probable cases of Zika and only $14 \%$ for dengue. This result was compatible with the perceptions of physicians working at the service (personal communication), suggesting that most of the reported cases of dengue that same year were, in fact, cases of Zika. The Ministry of Health in Brazil, owing to a lack of reliable official data, estimated the number of cases in Brazil based on reports of attack rates from other countries; it was suggested that there may have been between 497,000 and 1,482,701 cases of Zika in Brazil ${ }^{(18)}$.

After the outbreak in Brazil, Colombia was the second country to be affected, with an epidemic peak in February 2016. In February 2016, the World Health Organization declared the Zika outbreak an international public health emergency. Until May 2016, 60 countries reported local transmission of the virus, 39 of which are in the Americas ${ }^{(19)(20)}$.

\section{OTHER ROUTES OF TRANSMISSION}

In addition to vector-based transmission via mosquitoes, other routes of transmission have been reported and studied. These include sexual transmission, and transmission via breast feeding or blood product transfusion.

\section{Sexual transmission}

One of the first reports of sexual transmission occurred in 2008 when an American researcher returning from Senegal developed Zika symptoms, and so did his wife, being ZIKV infection confirmed by serologic tests in the man and his wife $\mathrm{w}^{(21)}$. In February 2016, the Centers for Disease Control (CDC) received 14 reports of suspected cases of sexual transmission of Zika in the United States; 3 had laboratory confirmation ${ }^{(22)}$. Confirmation of sexual transmission was also reported by other countries ${ }^{(23)(24)(25)}$. Recent publications reinforce that ZIKV is excreted in semen ${ }^{(26)}$ (27) (28). In France, researchers determined that viral loads were 100,000 times greater in the semen than in blood or urine two weeks after the onset of the symptoms ${ }^{(27)}$. In the United Kingdom, ZIKV was isolated by RT-PCR in the semen sample of a 68 year old man 62 days after having had acute ZIKV infection ${ }^{(28)}$. Given the new evidence, the CDC and the UK government recommended that partners coming/returning from countries with ZIKV abstain from sex or use condoms for at least 8 weeks if they had no symptoms of ZIKV infection, or for 6 months if they had clinical features or confirmation of ZIKV infection. This recommendation was extended for the duration of pregnancy for those with pregnant partners ${ }^{(29)}{ }^{(30)}$.

\section{Breastfeeding}

In a study, samples of the breast milk from 2 women who were infected with ZIKV tested positive for the virus by RTPCR. However, no replication of viral particles was detected in the cell cultures, making this an unlikely route of transmission ${ }^{(31)}$.

\section{Blood transfusion}

During the Zika outbreak in French Polynesia (2013-2014), blood samples of 1,505 blood donors were analyzed; ZIKV was detected by RT-PCR in $42(3 \%)$ samples. Eleven (26\%) of these patients reported having developed symptoms of ZIKV infection 3-10 days after donating blood ${ }^{(32)}$. In Brazil, a report was published in the international press of a case in which ZIKV was detected in a blood recipient, although the recipient did not develop any symptoms ${ }^{(33)}$.

\section{CLINICAL SPECTRUM}

Classical form and the definition of a suspected case: there are few cohort or other observational studies describing the frequency of symptoms of ZIKV infection. Those that do exist present different methodologies and discordant results, making to the definition of a suspected case difficult. One of the first reports to describe clinical findings of laboratory confirmed ZIKV infection was from 1964 in Uganda. In that report, a 28-year-old man presented with a headache and, on the second day of the illness, developed a proximal rash. He did not have a fever, only a slight discomfort, and had no arthralgia, 
joint swelling, or conjunctivitis ${ }^{(2)}$. In the outbreak in Yap Island in 2007, 31 cases were analyzed. Rash was the predominant symptom, present in $90 \%$ of the patients, while fever (measured or stated) was reported in $65 \%$. Arthritis and arthralgia were common clinical features, being observed in $65 \%$ of patients, and conjunctivitis was present in $55 \%$ of cases $^{(4)(7)}$.

The definitions of suspected cases used later by French Polynesia and, most recently, by the Pan American Health Organization (PAHO) came from these cases series. The definition of a suspected case, according to the latest guide of the PAHO, is the presence of exanthema and at least two of the following signs and symptoms: low-grade fever (temperature $<38.5^{\circ} \mathrm{C}$ ), conjunctivitis, arthralgia, myalgia, or swollen joints ${ }^{(5)(34)}$.

Two other studies, with a greater number of cases, present different frequencies of these symptoms. In a prospective study by Brazil et al. ${ }^{(35)}$, performed in Rio de Janeiro among 262 patients with a history of acute onset rash with or without fever. Of these, 119 laboratory-confirmed cases of ZIKV infection, with rash in $97 \%$ of the confirmed cases and only $36 \%$ of the cases experienced fever not that lasted more than a day and was reported only once. There was a low frequency of joint swelling (29\%) among cases $^{(35)}$. In Mexico, 99 confirmed cases were identified via the epidemiological surveillance system. Their data, obtained from report forms, were retrospectively analyzed. Fever was reported in $96.6 \%$ of the cases, rash in $96.6 \%$, conjunctivitis in $88.8 \%$, and arthritis in $16 \%{ }^{(36)}$.

The PAHO criteria require, in addition to exanthema, the presence of two other symptoms. This decreases sensitivity and can lead to under reporting of cases. Exanthema may be the only manifestation of ZIKV infection. This differentiates Zika from other arboviral infections, not only by the high frequency (90-100\%) of rash, but also by its timing, appearing in the first 72 hours of infection ${ }^{(18)}$. In the cohort of Brazil et al. ${ }^{(35)}$, symptoms such as fever and joint swelling were infrequent and other symptoms, such as arthralgia and myalgia, were present in $\sim 60 \%$ of cases. Hence, laboratory-confirmed cases may not fulfill the criteria required for suspected cases.

In the report on 115 cases of ZIKV infection among US residents who were in areas of ZIKV circulation, different from other case series, only $37 \%$ had conjunctivitis. In this study, $65 \%$ of cases presented with 3 symptoms or more ${ }^{(37)}$. According to the PAHO criteria, that require the presence of at least 3 of the key symptoms, $35 \%$ of the patients did not fulfill the diagnostic criteria. The authors suggest that broader criteria for suspected cases be used, and that ZIKV should be considered in patients with fever of acute onset, rash, arthralgia or conjunctivitis ${ }^{(37)}$.

In Pernambuco, 2 of the first 7 RT-PCR-confirmed adult cases with neurological symptoms presented with only a rash and another had a rash and conjunctivitis; therefore, none of these 3 cases would have been considered suspects according to the PAHO definition ${ }^{(38)}$. The first confirmed case of ZIKV infection in the world, who presented only with a rash, would also not have been detected using the case definition adopted by $\mathrm{PAHO}^{(2)}$.

In outbreaks of arboviral infections in the Americas, after confirmation of viral circulation, diagnostic tests are not performed on all cases; all subsequent notifications are based on clinical and epidemiological features using the case definition. This limits laboratory research on severe and atypical cases. The diagnosis, based not only on the presence of symptoms but also on the pattern and the chronological order of their appearance, allows the differentiation of arboviral etiology in most cases (Table 1).

The frequency difference in the clinical findings among studies has led countries to adopt different case definitions or to choose less sensitive case definitions. This reinforces the need for more descriptive studies to standardize these criteria, and for making surveillance systems more sensitive to case reporting based on clinical criteria.

Numerous guidelines and review articles report that $80 \%$ patients infected with ZIKV are asymptomatic ${ }^{(6)}(11)(18)(39)(40)(41)$. This is based mainly on a single seroprevalence study involving a small number of cases on Yap Island. However, reports of the large numbers of patients attending health units during the outbreak in many Latin American countries, suggest a higher symptomatic proportion. Among cases of neonatal microcephaly, approximately $60-70 \%$ of the pregnant women were symptomatic ${ }^{(42)(43)}$ and among the confirmed cases of associated GBS, $88 \%$ were symptomatic after infection with ZIKV, reinforcing the need for other seroprevalence studies with larger case by case studies to define the actual symptomatic percentage.

\section{Neurological involvement}

The appearance of neurological cases potentially associated with ZIKV infection was initially described in French Polynesia in 2013. Thirty-nine cases of GBS were reported after the outbreak, but ZIKV was not isolated from these patients ${ }^{(5)}(7)$. In the Northeast of Brazil, from April 2015 an increase in the number of neurological cases was noticed ${ }^{(12)}$. Confirmation of the association took place in the State of Pernambuco, where positive results for ZIKV were obtained by RT-PCR and viral isolation from 7 serum samples and 1 amniotic fluid sample. Of these 7 cases, 4 presented with GBS, 2 with acute disseminated encephalomyelitis, and one with meningoencephalitis. A further 70 neurological cases are under investigation, aiming to clarify details of the outbreak ${ }^{(12)(38)}$. Seven other Latin countries reported an increase in the number of GBS cases ${ }^{(19)}$.

Recently, ZIKV infection was confirmed by serologic testing of the stored serum samples of 41 patients who had GBS in French Polynesia in 2013. The pattern of acute motor axonal neuropathy was predominant among the cases (74\%). The average time from infection to the development of neurological symptoms was 6 days ${ }^{(44)}$. A recent publication questioned the interpretation of the serologic tests performed, stating that the laboratory results were inconclusive due to potential cross reaction of dengue ${ }^{(45)}$.

The first report on the pathogenesis of the virus was described by Dick et al. ${ }^{(4)}$ in an animal model published in 1952. Inoculating ZIKV into mice triggered motor weakness and paralysis of the limbs, with viral replication detected in the brain tissue, suggesting neurotropism of the virus. The short time between the clinical presentation of ZIKV infection and 
TABLE 1

Differential features of disease caused by Zika virus and other arboviruses.

\begin{tabular}{|c|c|c|c|}
\hline Signs/symptoms & Dengue & Zika & Chikungunya \\
\hline Fever & $\operatorname{High}\left(>38^{\circ} \mathrm{C}\right)$ & None or low-grade $\left(\leq 38^{\circ} \mathrm{C}\right)$ & $\operatorname{High}\left(>38^{\circ} \mathrm{C}\right)$ \\
\hline Duration of fever, (days) & $4-7$ & $1-2$ & $2-3$ \\
\hline Rash, timing of appearance & $4^{\text {th }}$ day of infection & $1^{\text {st }}$ or $2^{\text {nd }}$ day of infection & Within 2-5 days of infection \\
\hline Rash, frequency & $30-50 \%$ of cases & $90-100 \%$ of cases & $50 \%$ of cases \\
\hline Myalgia (frequency) & +++ & ++ & + \\
\hline Arthralgia (frequency) & + & ++ & +++ \\
\hline Intensity of arthralgia & Mild & Mild/moderate & Moderate/intense \\
\hline Joint swelling & Rare & Frequent; mild intensity & Frequent; moderate to severe intensity \\
\hline Pink eye & Rare & $50-90 \%$ of cases & $30 \%$ of cases \\
\hline Headache & +++ & ++ & ++ \\
\hline Lymphadenopathy & + & +++ & ++ \\
\hline Hemorrhagic dyscrasia & ++ & Absent & + \\
\hline Risk of death & +++ & $+*$ & ++ \\
\hline Neurological involvement & + & +++ & ++ \\
\hline Leukopenia & +++ & +++ & +++ \\
\hline Lymphopenia & Uncommon & Uncommon & Common \\
\hline Thrombocytopenia & +++ & Absent & ++ \\
\hline
\end{tabular}

*There may be arisk of death in cases such as neurological Guillain-Barre syndrome resulting from Zika virus infection or for children with severe congenital malformations.

the appearance GBS, as reported in French Polynesia ${ }^{(44)}$, may indicate a direct neuropathic effect of the virus, in addition to an immune-mediated effect that damages the peripheral nerves and spinal roots weeks after clinical presentation of the acute viral infection. These and other questions are to be clarified from future studies on the immunopathogenesis of ZIKV.

\section{Microcephaly: from suspicion to confirmation of the association}

In October 2015, neurologists and neonatologists in the State of Pernambuco observed a major increase in the number of cases of neonatal microcephaly. A clinician with experience in outbreaks (Dr. Carlos Brito) was called by physicians to give an opinion on the occurrence and began to investigate. In a single maternity hospital, a referral hospital in the state, 26 neonates with microcephaly were hospitalized simultaneously. There were 58 cases in a single month, far exceeding the total number of cases registered in previous years ( 5 in 2011, 9 in 2012, 10 in 2013, and 12 in 2014). Primary and secondary causes were suggested, but the initial investigation of these cases made the physician raise the hypothesis of $\mathrm{ZIKV}^{(10)(11)(12)}$, based on the following clinical and epidemiological evidence: a) many cases appeared in a short time, occurring simultaneously in different cities and states, characteristic of a disease with a high attack rate and rapid dissemination, a phenomenon associated with diseases transmitted by arthropods; b) in addition to microcephaly, imaging tests showed some common findings: Periventricular and cortical micro-calcifications, hypoplasia cerebellar and, in some cases,lissencephaly, compatible with congenital infections which were later described in detail ${ }^{(47)}$; c) diseases associated with TORCH (toxoplasmosis, rubella, cytomegalovirus, syphilis, human immunodeficiency virus, parvovirus B19), because of their modes of transmission, are not associated with major outbreaks; d) prenatal and perinatal research revealed negative test results for TORCH infections; e) most $(70 \%)$ mothers reported a clinical presentation compatible with ZIKV infection in their first trimester of pregnancy, which took place during a period in which there was a ZIKV outbreak in the region; f) ZIKV has a greater neurotropism than other arboviruses; g) other arboviral infections endemic and epidemic in the region, such as dengue or Chikungunya, are not associated with congenital malformations Moreover, Chikungunya had not been detected in many Northeast states in the beginning of the year.

The growing number of cases made the Ministry of Health declare a national health emergency in the state 25 days after beginning the research ${ }^{(18)}$. RT-PCR testing and virus isolation from the amniotic fluid and blood samples of the first cases were negative, probably because the infection had occurred in the first trimester of pregnancy. The first laboratory confirmation came on November 17, 2015, when a specialist in fetal medicine in Paraíba State (Dr. Adriana Melo), identified ZIKV by RT-PCR 
in the amniotic fluid of two pregnant women whose fetuses presented with microcephaly ${ }^{(48)}{ }^{(49)}$. On November 28, the Evandro Chagas Institute detected the ZIKV in the blood and tissue samples of two stillborn infants with microcephaly ${ }^{(18)}$.

No cases of microcephaly were reported in the Zika outbreak in French Polynesia in 2013. However, in November 2015 after the Brazilian alert, 17 cases involving changes in the central nervous system were recognized, including 12 cases of microcephaly ${ }^{(31)}{ }^{(49)}$. In March 2016, ZIKV was confirmed by RT-PCR performed on the stored amniotic fluid samples of 4 of these cases ${ }^{(50)}$. In the following months, other studies were published confirming the association. In December 2015, tissue samples from 2 stillborn infants with microcephaly and 2 fetuses from miscarriages in Rio Grande do Norte tested positive for ZIKV, both by RT-PCR and using immunohistochemistry ${ }^{(51)}$.

In 2016, the Hawaii an government confirmed a case of microcephaly. The mother was pregnant while in Brazil in May 2015, during which time she had acquired ZIKV infection ${ }^{(52)}$. A second case of fetal microcephaly occurred in Slovenia; the pregnant mother was infected with ZIKV while in Brazil. She miscarried, and the presence of ZIKV was identified by RT-PCR in the brain tissue of the fetus ${ }^{(53)}$. The evidence that most cases microcephaly that affected this country was due to ZIKV infection came in a recent publication that reported that ZIKV-specific IgM was detected in 30 amniotic fluid samples of the first 31 microcephaly cases in Pernambuco. IgM does not pass the placental barrier; hence, its presence in amniotic fluid confirms infection in the fetus ${ }^{(54)}$.

In addition to microcephaly, other anomalies began to be identified, including arthrogryposis, other musculoskeletal malformations ${ }^{(48)}$, and hearing and visual disorders ${ }^{(55)}$. These may be related to the time of the infection, reinforcing the need to expand the investigation and broaden the spectrum as a syndrome associated with congenital ZIKV infection or simply congenital ZIKV following the example of other congenital infections $^{(10)}$.

\section{LABORATORY DIAGNOSIS}

The laboratory diagnosis of infection by ZIKV, within the first 5-7 days of infection, includes techniques for the detection of the viral genome (RT-PCR and/or RT-PCR in real time) or viral isolation in cell culture. The viral load is lower in blood than inurine. In urine, the virus may be detected with 15-20 days. The serological tests for detection of specific ZIKV antibodies may confirm the diagnosis, provided that they are conducted and interpreted with criteria, since cross-reaction between the flaviviruses is possible ${ }^{(56)}$.

ZIKV-specific IgM antibodies are formed during the first week of the disease and may be detected from day 7 on. Two serum samples must be analyzed; one during the acute phase and another during the convalescent phase (14-21 days). Samples must be tested simultaneously for antibodies to ZIKV, dengue fever, and other flaviviruses endemic in the region ${ }^{(56)}$. Due to the lack of commercial kits for the detection of ZIKV-specific $\operatorname{IgM}$ and IgG antibodies, the reference laboratories use inhouse enzyme-linked immunosorbent assays for IgM research.
These are verified as effective, with good sensibility and specificity, and have been validated and certified by international institutions of reference. In pregnant women and in severe cases, it is recommended that positive IgM serology be confirmed by the more specific plaque reduction neutralization test ${ }^{(57)}$.

\section{THE FUTURE}

Short-term actions should focus on combatting the vector, aiming to reduce its density. Medium and long-term actions should aim for the development of antiviral therapies, particularly for pregnant women following exposure to ZIKV, and the development of a vaccine.

\section{Conflict of interest}

The authors declare that there is no conflict of interest.

\section{REFERENCES}

1. Dick GWA, Kitchen SF, Haddow AJ. Zika virus. I. Isolations and serological specificity. Trans R Soc Trop Med Hyg 1952; 46:509530.

2. Simpson DIH. Zika virus infection in man. Trans R Soc Trop Med Hyg 1964; 58:335-337.

3. Macnamara FN. Zika virus: areport on three cases of human infection during an epidemic of jaundice in Nigeria. Trans R Soc Trop Med Hyg 1954; 48:139-145.

4. Duffy MR, Chen T-H, Hancock TW, Powers AM, Kool JL, Lanciotti RS, et al. Zika virus outbreak on Yap Island, Federated States of Micronesia. N Engl J Med 2009; 360:2536-2543.

5. Polynésie Française. Surveillance de la dengue et du zika en Polynésie française. Données actualisées au 28 février 2014. Bulletin Zika Dengue2014.p. 6-9. Available in: http://www.hygienepublique.gov.pf/IMG/pdf/bulletin_zika-dengue_.pdf.

6. Ioos S, Mallet H-P, Leparc Goffart I, Gauthier V, Cardoso T, Herida M. Current Zika virus epidemiology and recent epidemics. Med Mal Infect 2014; 44:302-307.

7. European Center for Disease Prevention and Control (ECDC). Rapid risk assessment: Zika virus infection outbreak, French Polynesia. Stockholm: ECDC 2014. p. 1-12.

8. Campos GS, Bandeira AC, Sardi SI. Zika virus outbreak, Bahia, Brazil. Emerg Infect Dis 2015; 21:1885-1886.

9. Zanluca C, de Melo VCA, Mosimann ALP, dos Santos GIV, dos Santos CND, Luz K. First report of autochthonous transmission of Zika virus in Brazil. Mem Inst Oswaldo Cruz 2015; 110:569-572.

10. Brito C. Zika virus : a New Chapter in the History of Medicine. Acta Med Port 2015; 28:679-680.

11. Teixeira MG, Costa MCN, de Oliveira WK, Nunes ML, Rodrigues LC. The epidemic of Zika virus-related microcephaly in Brazil: detection, control, etiology, and future scenarios. Am J Public Health 2016; 106:601-605.

12. Becker R. Missing link: animal models to study whether Zika causes birth defects. Nat Med 2016; 22:225-227.

13. Rodhain F, Gonzalez JP,Mercier E, HelyncK B, Larouze B, Hannoun C. Arbovirus infections and viral haemorrhagic fevers in Uganda: a serological survey in Karamoja district, 1984. Trans R Soc Trop Med Hyg 1989; 83:851-854.

14. Fagbami AH. Zika virus infections in Nigeria: virological and seroepidemiological investigations in Oyo State. J Hyg 1979; 83:213-219. 
15. Aubry M, Finke J, Teissier A, Roche C, Broult J, Paulous S, et al.Seroprevalence of arboviruses among blood donors in French Polynesia, 2011-2013. Int J Infect Dis 2015; 41:11-12.

16. Secretaria de Saúde de Pernambuco. Secretaria-Executiva de Vigilância em Saúde (SEVS).Circulação da Febre do Zika Vírus em Pernambuco - Orientações para a Vigilância e a Assistência à Saúde. Recife: 2015. p. 1-4.

17. Ministério da Saúde. Secretaria de Vigilância em Saúde. Monitoramento dos casos de microcefalias no Brasil, até a semana epidemiológica 46, 2015. Boletim Epidemiológico;vol. 46, nº 37, 2015. p. 1-6.

18. Ministério da Saúde. Secretaria de Atenção à Saúde. Protocolo de Atenção à Saúde e Resposta à Ocorrência de Microcefalia Relacionada à Infecção pelo Vírus Zika. Brasília: 2015. p. 1-49.

19. Pan American Health Organization/World Health Organization. Zika - Epidemiological Update. Washington: 2016. p. 1-8.

20. World Health Organization(WHO). Zika situation report. 2016. Available from: http://www.who.int/emergencies/zika-virus/ situation-report/4-march-2016/en/.

21. Foy BD, Kobylinski KC, Foy JLC, Blitvich BJ. Probable non-vectorborne transmission of Zika virus, Colorado, USA. Emerg Infect Dis 2011; 17:880-882.

22. Hills SL, Russell K, Hennessey M, Williams C, Oster AM, Fischer $\mathrm{M}$, et al. Transmission of Zika virus through sexual contact with travelers to areas of ongoing transmission- Continental United States, 2016. MMWRMorb Mortal Wkly Rep 2016; 65:215-216.

23. Venturi G, Zammarchi L, Fortuna C, Remoli ME, Benedetti E, Fiorentini C, et al. An autochthonous case of Zika due to possible sexual transmission, Florence, Italy, 2014. EuroSurveill 2016; 21:1-4. doi: 10.2807/1560-7917.ES.2016.21.8.30148.

24. McCarthy M. Zika virus was transmitted by sexual contact in Texas, health officials report. BMJ 2016;352:i720. Available from: http://www.bmj.com/content/352/bmj.i720.

25. Deckard DT, Chung WM, Brooks JT, Smith JC, Woldai S, Hennessey $\mathrm{M}$, et al. Male-to-male sexual transmission of Zika virus - Texas, January 2016.MMWR Morb Mortal Wkly Rep 2016; 65:372-374.

26. Musso D, Roche C, Robin E, Nhan T, Teissier A, Cao-Lormeau VM. Potenial sexual transmission of Zika virus. Emerg Infect Dis 2015; 21:359-361.

27. Mansuy JM, Dutertre M, Mengelle C, Fourcade C, Marchou B, Delobel P, et al.. Zika virus : high infectious viral load in semen, a new sexually transmitted pathogen? Lancet Infect Dis 2016; 16:405. doi: 10.1016/S1473-3099(16)00138-9.

28. Atkinson B, Hearn P, Afrough B, Lumley S, Carter D, Aarons EJ, et al. Detection of Zika virus in semen. Emerg Infect Dis 2016; 22:doi: 10.3201/eid2205.160107.

29. Oster AM, Russell K, Stryker JE, Friedman A, Kachur RE, Petersen EE, et al. Update: Interim Guidance for Prevention of Sexual Transmission of Zika Virus - United States, 2016. MMWR Morb Mortal Wkly Rep 2016; 65:323-325. Available from: http://www. ncbi.nlm.nih.gov/pubmed/27032078

30. Public Health England. United Kingdom. Guidance Zika virus: travel advice. Part of: Zika virus (ZIKV): clinical and travel guidance. England: 2016. p. 1-12. Available from: www.gov.uk/ guidance/zika-virus.

31. Besnard M, Lastère S, Teissier A, Cao-Lormeau VM, Musso D. Evidence of perinatal transmission of Zika virus, French Polynesia, December 2013 and February 2014. Euro Surveill 2014; 19:pii: 20751. Available from: www.eurosurveillance.org:pii $=20751$

32. Musso D, Nhan T, Robin E, Roche C, Bierlaire D, Zisou K, et al. Potential for Zika virus transmission through blood transfusion demonstrated during an outbreak in French Polynesia November
2013 to February 2014. Euro Surveill 2014; 19:pii: 20761. Available from: www.ncbi.nlm.nih.gov/pubmed/24739982

33. Reuters News Agency. Brazil reports Zika infection from blood transfusions. 2016. p. 6-8. http://www.reuters.com/article/ushealth-zika-brazil-blood-idUSKCN0VD22N.

34. Pan American Health Organization/World Health Organization (PAHO). Guía para la vigilancia de la enfermedad por el virus del Zika y sus complicaciones. 2015. p. 1-60.

35. Brasil P, Calvet GA, Siqueira AM, Wakimoto M, de Sequeira PC, Nobre A, et al. Zika virus outbreak in Rio de Janeiro, Brazil: clinical characterization, epidemiological and virological aspects. PLoS Negl Trop Dis 2016; 10:e0004636. doi: 10.1371/journal. pntd.0004636

36. Jimenez Corona ME, de la Garza Barroso AL, Rodriguez Martínez JC, Luna Guzmán NI, Ruiz Matus C, Díaz Quiñonez JA, et al. Clinical and epidemiological characterization of laboratory-confirmed autochthonous cases of Zika virus disease in Mexico. PLoS Curr 2016; 8:doi: 10.1371/currents.outbreaks.a2felb3d6d71e24ad2b5afe982824053.

37. Armstrong P, Hennessey M, Adams M, Cherry C, Chiu S, Harrist A, et al. Travel-associated Zika virus disease cases among U.S. residents - United States, January 2015-February 2016. Morb Mortal Wkly Rep 2016; 65:286-289.

38. Pan American Health Organization/World Health Organization (PAHO). Epidemiological Alert . Neurological syndrome, congenital malformations, and Zika virus infection. Implications for public health in the Americas. 1 December 2015. p. 1-11.

39. European Center for Disease Prevention and Control (ECDC). Rapid Risk Assessment. Zika virus disease epidemic: potential association with microcephaly and Guillain-Barré syndrome. Fifth update, 11 April 2016. Stockholm: ECDC 2016. p. 1-18.

40. Petersen LR, Jamieson DJ, Powers AM, Honein MA. Zika Virus. N Engl J Med 2016; 374:1552-1263. Available from: https:/www. ncbi.nlm.nih.gov/pubmed/27028561

41. Paixão ES, Barreto F, Teixeira MG, Costa MC, Rodrigues LC. History, epidemiology, and clinical manifestations of Zika: a systematic review. Am J Public Health 2016; 106:606-612.

42. Microcephaly Epidemic Group. Microcephaly in infants, Pernambuco State, Brazil, 2015. Emerg Infect Dis 2016; 22:doi: 10.3201/eid2206.160062.

43. Miranda-Filho DB, Martelli CMT, De Alencar Ximenes RA, Araújo TVB, Rocha MAW, Ramos RCF, et al. Initial description of the presumed congenital Zika syndrome. Am J Public Health. 2016; 106:598-600.

44. Cao-Lormeau VM, Blake A, Mons S, Lastère S, Roche C, Vanhomwegen J, et al. Guillain-Barré Syndrome outbreak associated with Zika virus infection in French Polynesia: a casecontrol study. Lancet 2016; 387:1531-1539.

45. Smith DW, Mackenzie J. Zika virus and Guillain-Barré syndrome: another viral cause to add to the list. Lancet 2016; 387:1486-1148.

46. Dick GWA. Zika virus. II. Pathogenicity and physical properties. Trans R Soc Trop Med Hyg 1952; 46:521-534.

47. Hazin AN, Poretti A, Turchi Martelli C, Huisman TA, Microcephaly Epidemic Research Group, Di Cavalcanti Souza Cruz D, et al. Computed tomographic findings in microcephaly associated with Zika virus. N Engl J Med 2016; 374:2193-2195.

48. Oliveira Melo AS, Malinger G, Ximenes R, Szejnfeld PO, Alves Sampaio S, Bispo de Filippis AM. Zika virus intrauterine infection causes fetal brain abnormality and microcephaly: tip of the iceberg?. Ultrasound Obstet Gynecol. 2016; 47:6-7

49. Calvet G, Aguiar RS, Melo ASO, Sampaio SA, de Filippis I, Fabri A, et al. Detection and sequencing of Zika virus from amniotic fluid of 
fetuses with microcephaly in Brazil: a case study. Lancet Infect Dis 2016; 16:653-660.

50. Jouannic JM, Friszer S, Leparc-Goffart I, Garel C, Eyrolle-Guignot D. Zika virus infection in French Polynesia. Lancet 2016; 387:10511052. doi: 10.1016/s0140-6736(16)00625-5

51. Martines RB, Bhatnagar J, Keating MK, Silva-Flannery L, Muehlenbachs A, Gary J, et al. Notes from the field: evidence of Zika Virus infection in brain and placental tissues from two congenitally infected newborns and two fetal losses - Brazil, 2015. MMWR Morb Mortal Wkly 2016; 65:159-160.

52. Centers ofr Disease Control and Prevention (CDC). DOH News Release: Hawaii Department of Health Receives Confirmation of Zika Infection in Baby Born with Microcephaly. Vol. 03. 2016. p. 2-3. Available from: http:// governor.hawaii.gov/newsroom/doh-news-release-hawaii-department

53. Mlakar J, Korva M, Tul N, Popović M, Poljšak-Prijatelj M, Mraz J, et al. Zika Virus associated with microcephaly. N Engl J Med 2016; 374:951-958.
54. Cordeiro MT, Pena LJ, Brito CA, Gil LH, Marques ET. Positive IgM for Zika virus in the cerebrospinal fluid of 30 neonates with microcephaly in Brazil. Lancet 2016; 387:1811-1812. Available from: http://dx.doi.org/10.1016/S0140-6736(16)30253-7

55. Ventura CV, Maia M, Bravo-Filho V, Góis AL, Belfort Junior R. Zika virus in Brazil and macular atrophy in a child with microcephaly. Lancet 2016; 387:228. doi: 10.1016/S0140-6736(16)00006-4

56. Lanciotti RS, Kosoy OL, Laven JJ, Velez JO, Lambert AJ, Johnson AJ, et al. Genetic and Serologic properties of Zika virus associated with an epidemic, Yap State, Micronesia, 2007. Emerg Infect Dis 2008; 14:1232-1239.

57. Rabe IB, Staples JE, Villanueva J, Hummel KB, Johnson JA, Rose $\mathrm{L}$, et al. Interim Guidance for Interpretation of Zika Virus Antibody Test Results. MMWR Morb Mortal Wkly Rep 2016; 65: doi:http:// dx.doi.org/10.15585/mmwr.mm6521e1 